\title{
Non-invasive ventilation with intelligent volume- assured pressure support versus pressure- controlled ventilation: effects on the respiratory event rate and sleep quality in COPD with chronic hypercapnia
}

This article was published in the following Dove Press journal: International Journal of COPD

30 March 2017

Number of times this article has been viewed

\author{
Georg Nilius',2 \\ Nato Katamadze ${ }^{1,2}$ \\ Ulrike Domanski' \\ Maik Schroeder' \\ Karl-Josef Franke ${ }^{1,2}$ \\ 'HELIOS Klinik Hagen-Ambrock, \\ ${ }^{2}$ Internal Medicine I, Witten/Herdecke \\ University, Witten, Germany
}

Background: COPD patients who develop chronic hypercapnic respiratory failure have a poor prognosis. Treatment of choice, especially the best form of ventilation, is not well known. Objectives: This study compared the effects of pressure-controlled (spontaneous timed [ST]) non-invasive ventilation (NIV) and NIV with intelligent volume-assured pressure support (IVAPS) in chronic hypercapnic COPD patients regarding the effects on alveolar ventilation, adverse patient/ventilator interactions and sleep quality.

Methods: This prospective, single-center, crossover study randomized patients to one night of NIV using ST then one night with the IVAPS function activated, or vice versa. Patients were monitored using polysomnography (PSG) and transcutaneous carbon dioxide pressure $\left(\mathrm{PtcCO}_{2}\right)$ measurement. Patients rated their subjective experience (total score, 0-45; lower scores indicate better acceptability).

Results: Fourteen patients were included (4 females, age $59.4 \pm 8.9$ years). The total number of respiratory events was low, and similar under pressure-controlled (5.4 \pm 6.7$)$ and IVAPS $(8.3 \pm 10.2)$ conditions $(P=0.064)$. There were also no clinically relevant differences in $\mathrm{PtcCO}_{2}$ between pressure-controlled and IVAPS NIV (52.9 \pm 6.2 versus $49.1 \pm 6.4 \mathrm{mmHg}$ ). Respiratory rate was lower under IVAPS overall; between-group differences reached statistical significance during wakefulness and non-rapid eye movement sleep. Ventilation pressures were $2.6 \mathrm{cmH}_{2} \mathrm{O}$ higher under IVAPS versus pressure-controlled ventilation, resulting in a $20.1 \mathrm{~mL}$ increase in breathing volume. Sleep efficiency was slightly higher under pressure-controlled ventilation versus IVAPS. Respiratory arousals were uncommon (24.4/h [pressure-controlled] versus $25.4 / \mathrm{h}$ [IVAPS]). Overall patient assessment scores were similar, although there was a trend toward less discomfort during IVAPS.

Conclusion: Our results show that IVAPS NIV allows application of higher nocturnal ventilation pressures versus ST without affecting sleep quality or inducing ventilationassociated events.

Keywords: NIV, IVAPS, COPD, hypercapnia

\section{Introduction}

COPD is highly prevalent, with increasing rates of morbidity and mortality; it is estimated that COPD will become the fourth-most common cause of death by $2020 .{ }^{1}$ COPD patients who develop hypercapnia have a particularly poor prognosis. ${ }^{2-4}$ 
The pathophysiological processes underlying chronic hypercapnic respiratory insufficiency in COPD are not completely understood, but proposed mechanisms include increasing respiratory muscle insufficiency, ${ }^{5,6}$ increased dead volume ventilation ${ }^{7}$ and, in particular, changes in respiratory regulation during sleep. ${ }^{8}$ Compared with individuals with healthy lungs, COPD patients are more susceptible to hypoventilation during sleep; the extent of hypoventilation during sleep depends on the extent of pulmonary function impairment ${ }^{9}$ and occurs particularly during rapid eye movement (REM) sleep.

Nocturnal oxygen therapy increases the likelihood of sleep-related hypoventilation. ${ }^{10,11}$ Nocturnal non-invasive ventilation (NIV) is well established as an important treatment modality in patients with restrictive breathing disorders ${ }^{12-14}$ and has been associated with increases in quality of life and life expectancy in this group. However, the utility of NIV in the treatment of chronic hypercapnia in COPD patients has been a topic of debate. ${ }^{15-18}$ Currently available data are heterogeneous and patient populations studied have included those with more acute hypercapnia and/or chronic hypoventilation, for which the ventilation techniques applied were quite different. There are also data gaps regarding systematic evaluation of NIV-related side effects. In particular, sleep disturbances caused by triggering problems and/or leakage events have been largely ignored until now, although some groups have proposed assessing these problems in systematic studies. ${ }^{19,20}$

The aim of the current study was to compare NIV controlled by pressure only using a background rate (spontaneous timed [ST]) and NIV with intelligent volume-assured pressure support (IVAPS) in patients with COPD and chronic hypercapnia with respect to effects on alveolar ventilation, incidence of adverse patient/ventilator interactions and sleep quality.

\section{Methods}

\section{Study design and patients}

This prospective, single-center, randomized, crossover study included COPD patients aged 40-75 years with stable chronic hypercapnia (partial pressure of carbon dioxide $\left[\mathrm{pCO}_{2}\right]>50 \mathrm{mmHg}$ ). Exclusion criteria were a history of NIV use, tracheotomy, unstable concomitant diseases requiring intensive medical treatment, respiratory acidosis $(\mathrm{pH}<7.30)$ or a lack of cognitive capacity. The study was conducted in accordance with the Declaration of Helsinki. The study was approved by the ethics committee of the University of Witten/ Herdecke no 24/2013 and registered with ClinicalTrials.gov (NCT 01986413). All the patients provided written informed consent before being enrolled in the study.

\section{Study endpoints}

The primary endpoint of the study was the number of index events per hour. Secondary endpoints were sleep time, sleep quality, ventilation parameters and gas exchange.

\section{Interventions and assessments}

During an in-hospital stay of several days, eligible patients underwent NIV for the first time according to hospitalinternal clinical routine processes: pressure-controlled NIV (Stellar 150 system; Resmed, San Diego, CA, USA) was adjusted to reduce $\mathrm{pCO}_{2}$ to $<50 \mathrm{mmHg}$, measured by capillary blood samples in the morning about $1 \mathrm{~h}$ after the end of nocturnal ventilation. Inspiratory pressure was increased gradually. According to clinical practice, the selected backup rate was 2 breaths/min below the spontaneous breathing rate. Expiration pressure was found to be higher in patients who showed upper airway obstruction. NIV was delivered via either a nasal or oronasal mask, and the mask was carefully adjusted as part of routine clinical care.

At the end of the clinical NIV adjustment process and immediately before planned discharge, all the patients underwent polysomnography (PSG) with transcutaneous $\mathrm{CO}_{2}$ measurement on two consecutive nights during which they received NIV with standard pressure-controlled settings or with the IVAPS function activated; the order of treatment was randomized using randomization lists.

Full laboratory PSG (Alice5; Philips Respironics) was performed according to the American Academy of Sleep Medicine (AASM) recommendations. ${ }^{21}$ Flow, leakage, breath volume and pressure were recorded by the ventilation device and transferred to the PSG recording via the "TX-link" interface; in addition, transcutaneous $\mathrm{pCO}_{2}$ and oxygen saturation $\left(\mathrm{SaO}_{2}\right)$ were measured using transcutaneous capnometry (TOSCA, Radiometer) and also combined with PSG data. All data were anonymized and then manually scored using AASM criteria ${ }^{22}$ by a technician who was unaware of the type of ventilation given.

Based on international consensus group recommendations, ${ }^{19}$ the following NIV-associated events were defined: unintended leak (pressure amplitude drops, breathing effort remains constant or is reduced and flow from the device increases, or expiratory flow is limited [mouth leakage]); incorrect triggering (patient ventilator asynchrony, ventilator switches to the backup rate despite patient inspiration because this is not recognized due to leakage, pressure amplitude decreases, inspiratory flow is maintained, effort decreases and is not synchronous with the ventilator); central event (decrease in ventilatory drive, the effort signal amplitude falls to zero and there is no phase angle between thoracic and abdominal efforts; depending on the device mode, 
device flow shows the backup rate or a zero line [indicating central apnea/hypopnea]); obstructive event (obstructive apnea, obstructive hypopnea; flow amplitude falls rapidly while inspiratory pressure increases, effort signals show a phase shift); hypoventilation (flow amplitude drops slowly while $\mathrm{pCO}_{2}$ increases by $\geq 10 \mathrm{mmHg}$ [a minimum duration of $1 \mathrm{~min}$ was specified to account for the reaction time of the transcutaneous measurement method]).

All the patients were asked to complete a questionnaire at the end of each night of ventilation to rate the NIV therapy received (on a scale of $0-5$ for each question). This included five questions relating to physical and psychological reactions to the ventilation over the previous night (condition score; $0-25$ points) and four questions about airway-related adverse effects (side effects score; 0-20 points). The total possible score was $0-45$ points, where a lower score indicated better acceptability.

\section{Statistical analysis}

The study was designed to provide initial assessment of the relevance of the newly defined events. Therefore, there were no empirical data on which a sample size calculation could be based.

Descriptive statistics were applied to all data. Mean, median and standard deviation values were calculated for all patients. Comparisons of the primary endpoint between the two ventilation modes were based on comparative statistics using a Wilcoxon test. A post hoc comparison of the questionnaire with 13 items (secondary parameter) was done with Bonferroni-Holm correction.

\section{Results Study population}

A total of 21 patients with daytime hypercapnia were invited to participate in the study and were hospitalized for NIV titration between July 2013 and May 2014 (Figure 1); two patients declined to participate, underlying pulmonary disease was determined not to be COPD in four patients, one patient discontinued the study on the second night due to discomfort caused by the measurement setup. Therefore, only 14 patients were included in the final analysis (four females, age $59.4 \pm 8.9$ years, height $170.8 \pm 9.0 \mathrm{~cm}$, body weight $99.9 \pm 37.6 \mathrm{~kg}$ and body mass index $33.7 \pm 10.6 \mathrm{~kg} / \mathrm{m}^{2}$ ). Pulmonary function assessment indicated that patients had serious obstructive ventilation disorders (Global Initiative for Chronic Obstructive Lung Disease stage III-IV ${ }^{23}$ ) with a forced expiratory volume in $1 \mathrm{~s}\left(\mathrm{FEV}_{1}\right)$ of $1.0 \pm 0.5 \mathrm{~L} / \mathrm{min}(35.9 \% \pm 16.1 \%$ of predicted), forced vital capacity (FVC) of $1.9 \pm 0.7 \mathrm{~L}$ and $\mathrm{FEV}_{1} / \mathrm{FVC}$ ratio of $54.0 \% \pm 13.5 \%$; residual volume was

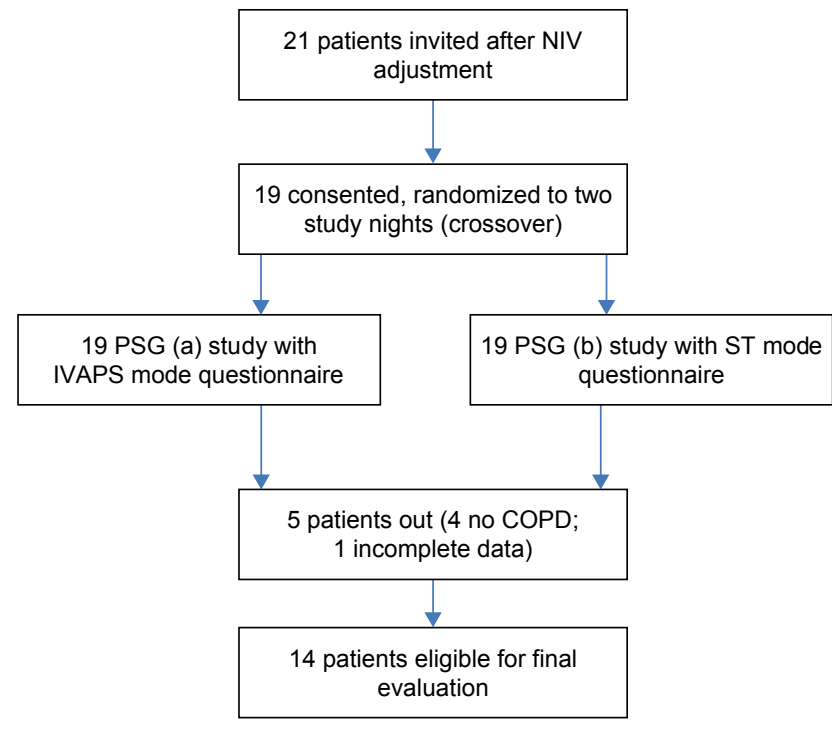

Figure I Study flow chart.

Abbreviations: IVAPS, intelligent volume-assured pressure support; NIV, noninvasive ventilation; PSG, polysomnography; ST, spontaneous timed.

4.6 $\pm 1.5 \mathrm{~L}$ (217.6\% $\pm 83.4 \%$ of predicted). CO diffusion was markedly reduced $(28.2 \% \pm 17.4 \%$ of predicted $)$.

Capillary blood gas analyses prior to initiation of NIV showed chronic hypercapnia (mean $\mathrm{pCO}_{2} 51.7 \pm 6.1 \mathrm{mmHg}$, base excess $6.3 \pm 3.1$ and bicarbonate $29.9 \pm 3.0 \mathrm{mmol} / \mathrm{L}$ ) without respiratory acidosis $(\mathrm{pH} 7.4 \pm 0.0)$. All the patients were hypoxemic $\left(\mathrm{pO}_{2} 56.9 \pm 10.2 \mathrm{mmHg}\right)$, four were receiving long-term oxygen therapy and six were diagnosed with obstructive sleep apnea.

\section{Respiratory events}

The overall number of ventilation-related respiratory events was very low in both NIV modes and there were no statistically significant differences between the two modes of ventilation (Table 1), although the overall event index was slightly higher under IVAPS compared with pressurecontrolled ventilation $(P=0.064)$. Obstructive hypopneas were the most frequent type of event detected during both ventilation modes (Table 1).

Table I Respiratory events

\begin{tabular}{llll}
\hline & IVAPS & ST & P-value \\
\hline UL, $\mathrm{n} / \mathrm{h}$ & $0.3 \pm 0.8$ & $0.0 \pm 0.0$ & 0.109 \\
Ventilator asynchrony (PVA), $\mathrm{n} / \mathrm{h}$ & $0.2 \pm 0.6$ & $0.6 \pm \mathrm{I} .5$ & 0.173 \\
PVA + UL, $\mathrm{n} / \mathrm{h}$ & $0.6 \pm \mathrm{I} .2$ & $0.6 \pm \mathrm{I} .5$ & 0.779 \\
Ventilatory drive, $\mathrm{n} / \mathrm{h}$ & $2.7 \pm 3.4$ & $\mathrm{I} .8 \pm 4.3$ & 0.158 \\
Obstructive hypopneas, $\mathrm{n} / \mathrm{h}$ & $5.1 \pm 8.1$ & $3.0 \pm 4.6$ & 0.087 \\
Central apneas + hypopneas, $\mathrm{n} / \mathrm{h}$ & $2.7 \pm 3.4$ & $\mathrm{I} .8 \pm 4.5$ & 0.158 \\
Overall events, $\mathrm{n} / \mathrm{h}$ & $8.3 \pm 10.2$ & $5.4 \pm 6.7$ & 0.064 \\
\hline
\end{tabular}

Note: Values are given as mean \pm standard deviation.

Abbreviations: IVAPS, intelligent volume-assured pressure support; PVA, patient ventilator asynchrony; ST, spontaneous timed; UL, unintended leak. 
Table 2 Other respiratory parameters

\begin{tabular}{|c|c|c|c|}
\hline & IVAPS & ST & $P$-value \\
\hline $\mathrm{SaO}_{2}$ during NREM, \% & $92.7 \pm 3.5$ & $91.0 \pm 3.8$ & 0.036 \\
\hline $\mathrm{SaO}_{2}$ during $\mathrm{REM}, \%$ & $92.2 \pm 4.4$ & $90.6 \pm 4.8$ & 0.169 \\
\hline Total $\mathrm{SaO}_{2}, \%$ & $92.6 \pm 3.5$ & $90.9 \pm 3.9$ & 0.034 \\
\hline $\begin{array}{l}\text { Respiratory rate during } \mathrm{W} \text {, } \\
\text { breaths/min }\end{array}$ & $17.4 \pm 4.0$ & $18.9 \pm 3.1$ & 0.026 \\
\hline $\begin{array}{l}\text { Respiratory rate during REM, } \\
\text { breaths/min }\end{array}$ & $16.0 \pm 1.9$ & $17.2 \pm 3.2$ & 0.064 \\
\hline $\begin{array}{l}\text { Respiratory rate during NREM, } \\
\text { breaths/min }\end{array}$ & $15.9 \pm 1.8$ & $17.6 \pm 3.4$ & 0.016 \\
\hline $\mathrm{PtcCO}_{2}$ during $\mathrm{W}, \mathrm{mmHg}$ & $46.0 \pm 6.1$ & $49.6 \pm 6.6$ & 0.307 \\
\hline $\mathrm{PtcCO}_{2}$ during $\mathrm{REM}, \mathrm{mmHg}$ & $51.4 \pm 6.3$ & $55.0 \pm 6.4$ & 0.139 \\
\hline $\mathrm{PtcCO}_{2}$ during NREM, $\mathrm{mmHg}$ & $50.0 \pm 6.6$ & $54.1 \pm 5.4$ & 0.078 \\
\hline Total $\mathrm{PtcCO}_{2}, \mathrm{mmHg}$ & $49.1 \pm 6.4$ & $52.9 \pm 6.2$ & 0.196 \\
\hline
\end{tabular}

Notes: Values are mean \pm standard deviation. $\mathrm{PtcCO}_{2}$, transcutaneous carbon dioxide pressure; $\mathrm{SaO}_{2}$, oxygen saturation.

Abbreviations: IVAPS, intelligent volume-assured pressure support; NREM, nonrapid eye movement; REM, rapid eye movement; ST, spontaneous timed; $\mathrm{W}$, wake.

\section{Gas exchange}

There were no statistically significant differences between the two ventilation modes in transcutaneous $\mathrm{CO}_{2}$ pressure (Table 2). Oxygen saturation overall and during non-rapid eye movement (NREM) sleep were statistically, but not clinically, significantly higher during IVAPS compared with pressure-controlled ventilation; between-group differences in $\mathrm{SaO}_{2}$ during REM sleep were not statistically significant (Table 2). Respiratory rate was lower under IVAPS overall, and during both REM and NREM; differences between groups reached statistical significance during wakefulness and NREM sleep (Table 2).

\section{Ventilation pressures}

Ventilation parameters are summarized in Table 3. Pressures were $2.6 \mathrm{cmH}_{2} \mathrm{O}$ higher under IVAPS versus pressure-controlled ventilation, resulting in a $20.1 \mathrm{~mL}$

Table 3 Ventilation parameters from device

\begin{tabular}{llll}
\hline & IVAPS & ST & P-value \\
\hline IPAP, $\mathrm{cmH}_{2} \mathrm{O}$ & $20.5 \pm 3.9$ & $17.9 \pm 4.1$ & $0.01 \mathrm{I}$ \\
EPAP, $\mathrm{cmH}_{2} \mathrm{O}$ & $5.3 \pm 1.3$ & $5.4 \pm 1.4$ & 0.317 \\
Leakage, $\mathrm{L} / \mathrm{min}$ & $6.9 \pm 10.3$ & $7.1 \pm 9.3$ & 0.399 \\
$\mathrm{TV}, \mathrm{mL}$ & $569.3 \pm 105.4$ & $549.2 \pm 243.5$ & 0.209 \\
$\mathrm{RMV}, \mathrm{L}$ & $9.7 \pm 1.8$ & $9.8 \pm 3.2$ & 0.463 \\
$\mathrm{RR}, \mathrm{n} / \mathrm{min}$ & $16.9 \pm 1.7$ & $18.0 \pm 3.4$ & 0.065 \\
Inspiratory time, sec & $1.2 \pm 0.3$ & $1.1 \pm 0.3$ & 0.100 \\
Spontaneously cycled breaths, \% & $38.1 \pm 25.3$ & $58.9 \pm 28.2$ & 0.007 \\
Alveolar ventilation, L/min & $7.7 \pm 1.6$ & & \\
\hline
\end{tabular}

Notes: Values are mean \pm standard deviation. Alveolar ventilation is estimated as the device's measured RMV minus correction factor.

Abbreviations: EPAP, expiratory positive airway pressure; IPAP, inspiratory positive airway pressure; IVAPS, intelligent volume-assured pressure support; $\mathrm{RMV}$, respiratory minute volume; RR, respiratory rate; ST, spontaneous timed; TV, tidal volume. increase in breathing volume, while respiratory minute volume was almost identical in the two ventilation modes. Under IVAPS, $61.9 \%$ of breaths were triggered by the ventilation device, meaning that the proportion of spontaneously cycled breaths was markedly higher under pressure-controlled ventilation (Table 3).

\section{Sleep time and quality}

Total sleep time (TST) and the duration of the individual sleep phases did not show any clinically relevant or statistically significant differences between the two ventilation modes (Table 4). Sleep efficiency (TST/time in bed) was slightly higher under pressure-controlled ventilation compared with IVAPS, due to a lower wake time after sleep onset (Table 4). Respiratory arousals were rare in both ventilation modes (Table 4).

\section{Patient evaluation}

Overall scores on the patient questionnaire were not markedly different between the two ventilation modes (Table 5), although scores for the question "How did you sleep last night?" tended to indicate less discomfort during v-IVAPS, and the daytime drowsiness was lower compared to pressurecontrolled ventilation (Table 5). After Bonferroni-Holm correction, these differences were not deemed significant.

\section{Discussion}

This study compared one night of pressure-controlled ventilation with a hybrid-type ventilation comprising pressurecontrolled ventilation with volume-assured pressure support, that is a defined volume/min (IVAPS), in COPD patients with chronic hypercapnia. The key differences between IVAPS

Table 4 Sleep parameters

\begin{tabular}{llll}
\hline & IVAPS & ST & P-value \\
\hline Total sleep time, min & $262.9 \pm 61 . I$ & $268.9 \pm 60.6$ & 0.778 \\
Sleep period time, min & $344.5 \pm 54.4$ & $326.3 \pm 59.9$ & 0.140 \\
Time in bed, min & $358.8 \pm 51.4$ & $332.1 \pm 57.3$ & 0.056 \\
NREM sleep, \% & $84.2 \pm 7.8$ & $85.4 \pm 7.4$ & 0.379 \\
REM sleep, \% & $15.8 \pm 7.8$ & $14.6 \pm 7.4$ & 0.379 \\
N3 sleep, \% & $29.2 \pm 16.3$ & $28.7 \pm 12.6$ & 0.727 \\
Sleep efficiency, \% & $73.9 \pm 16.1$ & $80.9 \pm 10.7$ & 0.272 \\
WASO, min & $83.1 \pm 65.8$ & $50.1 \pm 38.0$ & 0.233 \\
WASO/sleep period time, \% & $23.3 \pm 16.9$ & $15.2 \pm 11.4$ & 0.433 \\
Arousal index, n/h & $25.4 \pm 9.9$ & $24.4 \pm 7.5$ & 0.683 \\
Respiratory arousal index, $\mathrm{n} / \mathrm{h}$ & $4.2 \pm 3.1$ & $3.1 \pm 3.3$ & 0.510 \\
\hline
\end{tabular}

Note: Values are mean \pm standard deviation averaged of all patients. Abbreviations: IVAPS, intelligent volume-assured pressure support; NREM, non-rapid eye movement; REM, rapid eye movement; ST, spontaneous timed; WASO, wake time after sleep onset. 
Table 5 Questionnaire scores (total possible score: 0-45 points; lower scores indicate better patient acceptability)

\begin{tabular}{|c|c|c|c|}
\hline & IVAPS & ST & $P$-value \\
\hline \multicolumn{4}{|l|}{ Condition } \\
\hline How did you sleep last night? & $2.5 \pm 1.3$ & $1.3 \pm 1.4$ & 0.445 \\
\hline $\begin{array}{l}\text { How intensive is your daytime } \\
\text { drowsiness this morning? }\end{array}$ & $0.5 \pm 1.2$ & $2.0 \pm 1.8$ & 0.018 \\
\hline $\begin{array}{l}\text { How would you rate your } \\
\text { physical efficiency today? }\end{array}$ & $2.0 \pm 1.3$ & $2.3 \pm 1.1$ & 0.043 \\
\hline $\begin{array}{l}\text { How would you rate your } \\
\text { ability to concentrate today? }\end{array}$ & $1.0 \pm 0.9$ & $1.5 \pm 0.7$ & 0.249 \\
\hline How is your mood today? & $1.0 \pm 1.0$ & $1.0 \pm 1.0$ & $0.28 \mathrm{I}$ \\
\hline Total score & $7.0 \pm 3.6$ & $9.3 \pm 3.1$ & 0.108 \\
\hline \multicolumn{4}{|l|}{ Side effects } \\
\hline Dry mouth? & $2.5 \pm 1.8$ & $2.8 \pm 1.9$ & 0.554 \\
\hline Weeping? & $0.5 \pm 1.1$ & $0.5 \pm 1.3$ & 0.593 \\
\hline Feeling of coldness in the face? & $0.5 \pm 0.9$ & $0.0 \pm 1.0$ & 0.655 \\
\hline Feeling of pressure in the chest? & $0.0 \pm 0.0$ & $0.3 \pm 0.8$ & 0.655 \\
\hline Total score & $4.0 \pm 2.9$ & $4.3 \pm 3.0$ & 0.813 \\
\hline Overall score & $11.5 \pm 5.3$ & $13.5 \pm 4.2$ & 0.142 \\
\hline
\end{tabular}

Notes: Values are median \pm standard deviation, post hoc comparison with Bonferroni-Holm correction showed no significant differences.

Abbreviations: IVAPS, intelligent volume-assured pressure support; ST, spontaneous timed.

and pressure-controlled ventilation in our trial were the application of $2.6 \mathrm{~cm}$ higher inspiratory ventilation pressures, a lower respiratory rate, a higher proportion of mandatory breaths and a trend toward increased $\mathrm{CO}_{2}$ elimination. Under both modes of ventilation, the rates of ventilation-associated events/leakages, faulty triggering, obstruction of the upper airways and hypopneas were very low and there were no relevant differences between the two modes. Sleep quality was also similar when the two different ventilation modes were used. In contrast to other types of volume-assured ventilation, ${ }^{24}$ we did not find any increase in the number of arousals.

Published data on the role of home NIV in chronic hypercapnic COPD patients are inconsistent regarding effects on life expectancy and quality of life. A number of studies found no relevant improvements in prognosis, ${ }^{25,26}$ while others reported small improvements in prognosis together with improved quality of life ${ }^{27}$ or marked improvements in life expectancy. ${ }^{28,29}$ One potential explanation for these discrepancies could be that the consequences of ventilation rate in COPD patients with chronic hypercapnia were not sufficiently taken into account. Mean inspiration pressures were $12.9 \mathrm{cmH}_{2} \mathrm{O}$ in an Australian multicenter study, ${ }^{27} 21.0 \mathrm{cmH}_{2} \mathrm{O}$ in a trial conducted in the Netherlands ${ }^{26}$ and $21.6 \mathrm{cmH}_{2} \mathrm{O}$ in a German study. ${ }^{29}$ Ventilation pressures of $15 \mathrm{cmH}_{2} \mathrm{O}$ or less were not sufficient to increase alveolar ventilation in this patient group. In our study, the inspiratory positive airway pressure under pressure-controlled ventilation was found to be $17.9 \pm 4.1 \mathrm{cmH}_{2} \mathrm{O}$, a value intermediate to those in other studies mentioned earlier. When IVAPS was used, ventilation pressures were similar to those reported in the Dutch and German studies. ${ }^{26,29}$ By looking only at pressures and the study findings, it is possible to conclude that the higher pressures achieved with IVAPS would be associated with beneficial effects in day-to-day practice, as described in the previous studies..$^{26,29}$ Ventilation pressures for both ventilation modes studied in this trial were equal at the beginning of the night, but increased in the IVAPS group due to the total volume control, without any impact on subjective sleep quality. Our data suggest that the use of IVAPS might allow patients to better adapt to higher ventilation pressures in clinical practice, allowing easier implementation of successful NIV. It is possible that the ventilation pressure could also have increased under pressure-controlled conditions, but this would have required a longer habituation process and taken longer than the one night duration of our recordings.

Use of a higher backup breathing rate for the ventilator can reduce sleep quality. ${ }^{30}$ Therefore, the backup rate for pressure-controlled ventilation was set at two breaths below the rate of the patient's own breathing. Higher backup breathing rates also seem to have no relevant effect on $\mathrm{pCO}_{2}$ reduction during NIV in hypercapnic COPD. ${ }^{31} \mathrm{COPD}$ patients who also have coexisting obstructive sleep apnea (overlap syndrome) demonstrated an increase in functional residual capacity (FRC) due to shortened or aggravated inspiration. ${ }^{32}$ Looking at basic pathophysiology, it is possible to conclude that patients with obstructive airway disease could benefit from a low breathing rate because this might reduce the extent of overinflation by shifting the FRC to inspiration. ${ }^{33}$ In this study, the breathing rate decreased by $\sim 6 \%$ under IVAPS versus pressure-controlled conditions, along with higher inspiration pressure, but largely constant tidal volume. On the other hand, there was a tendency toward an increase in alveolar ventilation, as shown by a lower, but not significantly different transcutaneous carbon dioxide pressure $\left(\mathrm{PtcCO}_{2}\right)$. The proportion of mandatory breaths was obviously higher under IVAPS. This could be due to the lower $\mathrm{pCO}_{2}$ together with a reduction in intrinsic respiratory drive. On this basis, we hypothesize that a lower ventilation rate might offer a relevant benefit for these patients.

Some limitations must be noted: this study included only a small number of patients and it is possible that this contributed to the inability to demonstrate statistically significant reductions in $\mathrm{PtcCO}_{2}$ reduction or significant between-group differences in other assessed parameters (type 2 error). 
Alveolar ventilation was predicted from transcutaneous $\mathrm{CO}_{2}$ signal. A nightly blood gas analysis could have been more precise but might have disturbed the patients' sleep and caused some difficulties in the conduct and approval of the study.

Another limitation of the study is the application of each ventilation mode for only one night. Future studies should involve a systematic evaluation of the consequences of ventilation rates and ventilation pressures, both on pulmonary function parameters and quality of life, over the longer term.

\section{Conclusion}

The results of this study in stable hypercapnic COPD patients demonstrate that hybrid ventilation combining respiratory minute volume control and pressure-controlled ventilation (IVAPS) allows comparably effective ventilation compared with ventilation controlled by pressure only. But IVAPS makes it possible to apply higher nocturnal ventilation pressures, without any obvious effects on sleep quality or inducing ventilation-associated events.

\section{Acknowledgment}

The study was financially supported by a grant from ResMed. The sponsor had no influence on the study design, data acquisition, data analysis and writing of the manuscript.

\section{Disclosure}

The authors report no conflicts of interest in this work.

\section{References}

1. Murray CJ, Lopez AD. Measuring the global burden of disease. N Engl J Med. 2013;369(5):448-457.

2. Costello R, Deegan P, Fitzpatrick M, McNicholas WT. Reversible hypercapnia in chronic obstructive pulmonary disease: a distinct pattern of respiratory failure with a favorable prognosis. Am J Med. 1997;102(3): 239-244.

3. Funk GC, Breyer MK, Burghuber OC, et al. Long-term non-invasive ventilation in COPD after acute-on-chronic respiratory failure. Respir Med. 2011;105(3):427-434.

4. Slenter RH, Sprooten RT, Kotz D, Wesseling G, Wouters EF, Rohde GG. Predictors of 1-year mortality at hospital admission for acute exacerbations of chronic obstructive pulmonary disease. Respiration. 2013;85(1): $15-26$.

5. Petersson J, Glenny RW. Gas exchange and ventilation-perfusion relationships in the lung. Eur Respir J. 2014;44(4):1023-1041.

6. Roussos C, Macklem PT. The respiratory muscles. N Engl J Med. 1982; 307(13):786-797.

7. Calverley PM. Respiratory failure in chronic obstructive pulmonary disease. Eur Respir J Suppl. 2003;47:26s-30s.

8. Crinion SJ, McNicholas WT. Sleep-related disorders in chronic obstructive pulmonary disease. Expert Rev Respir Med. 2014;8(1):79-88.

9. Holmedahl NH, Overland B, Fondenes O, Ellingsen I, Hardie JA. Sleep hypoventilation and daytime hypercapnia in stable chronic obstructive pulmonary disease. Int J Chron Obstruct Pulmon Dis. 2014;9: 265-275.
10. O'Donoghue FJ, Catcheside PG, Ellis EE, et al. Sleep hypoventilation in hypercapnic chronic obstructive pulmonary disease: prevalence and associated factors. Eur Respir J. 2003;21(6):977-984.

11. Tarrega J, Anton A, Guell R, et al. Predicting nocturnal hypoventilation in hypercapnic chronic obstructive pulmonary disease patients undergoing long-term oxygen therapy. Respiration. 2011;82(1):4-9.

12. Annane D, Orlikowski D, Chevret S, Chevrolet JC, Raphael JC. Nocturnal mechanical ventilation for chronic hypoventilation in patients with neuromuscular and chest wall disorders. Cochrane Database Syst Rev. 2007;(4):CD001941.

13. Bourke SC, Tomlinson M, Williams TL, Bullock RE, Shaw PJ, Gibson GJ. Effects of non-invasive ventilation on survival and quality of life in patients with amyotrophic lateral sclerosis: a randomised controlled trial. Lancet Neurol. 2006;5(2):140-147.

14. Pinto AC, Evangelista T, Carvalho M, Alves MA, Sales Luis ML. Respiratory assistance with a non-invasive ventilator (Bipap) in MND/ ALS patients: survival rates in a controlled trial. J Neurol Sci. 1995; 129(Suppl):19-26.

15. COPD Working Group. Noninvasive positive pressure ventilation for chronic respiratory failure patients with stable chronic obstructive pulmonary disease (COPD): an evidence-based analysis. Ont Health Technol Assess Ser. 2012;12(9):1-51.

16. Shi JX, Xu J, Sun WK, Su X, Zhang Y, Shi Y. Effect of noninvasive, positive pressure ventilation on patients with severe, stable chronic obstructive pulmonary disease: a meta-analysis. Chin Med J. 2013; 126(1):140-146.

17. Struik FM, Lacasse Y, Goldstein R, Kerstjens HM, Wijkstra PJ. Nocturnal non-invasive positive pressure ventilation for stable chronic obstructive pulmonary disease. Cochrane Database Syst Rev. 2013;(6): CD002878.

18. Dretzke J, Blissett D, Dave C, et al. The cost-effectiveness of domiciliary non-invasive ventilation in patients with end-stage chronic obstructive pulmonary disease: a systematic review and economic evaluation. Health Technol Assess. 2015;19(81):1-246.

19. Gonzalez-Bermejo J, Perrin C, Janssens JP, et al. Proposal for a systematic analysis of polygraphy or polysomnography for identifying and scoring abnormal events occurring during non-invasive ventilation. Thorax. 2012;67(6):546-552.

20. Rabec C, Langevin B, Rodenstein D, et al. Ventilatory modes. What's in a name? Respir Care. 2012;57(12):2138-2139; author reply 2139-2150.

21. American Academy of Sleep Medicine. The AASM Manual for the Scoring of Sleep and Associated Events: Rules, Terminology and Technical Specifications. Darien, IL, USA: American Academy of Sleep Medicine; 2007.

22. Berry RB, Budhiraja R, Gottlieb DJ, et al. Rules for scoring respiratory events in sleep: update of the 2007 AASM Manual for the scoring of sleep and associated events. Deliberations of the sleep apnea definitions task force of the American Academy of Sleep Medicine. J Clin Sleep Med. 2012;8(5):597-619.

23. Global Strategy for the Diagnosis, Management and Prevention of COPD, Global Initiative for Chronic Obstructive Lung Disease (GOLD) 2016. Available from: http://goldcopd.org/. Accessed January 30, 2016.

24. Carlucci A, Fanfulla F, Mancini M, Nava S. Volume assured pressure support ventilation-induced arousals. Sleep Med. 2012;13(6):767-768.

25. Casanova C, Celli BR, Tost L, et al. Long-term controlled trial of nocturnal nasal positive pressure ventilation in patients with severe COPD. Chest. 2000;118(6):1582-1590.

26. Struik FM, Sprooten RT, Kerstjens HA, et al. Nocturnal non-invasive ventilation in COPD patients with prolonged hypercapnia after ventilatory support for acute respiratory failure: a randomised, controlled, parallel-group study. Thorax. 2014;69(9):826-834.

27. McEvoy RD, Pierce RJ, Hillman D, et al. Nocturnal non-invasive nasal ventilation in stable hypercapnic COPD: a randomised controlled trial. Thorax. 2009;64(7):561-566.

28. Borel JC, Pepin JL, Pison C, et al. Long-term adherence with noninvasive ventilation improves prognosis in obese COPD patients. Respirology. 2014;19(6):857-865. 
29. Kohnlein T, Windisch W, Kohler D, et al. Non-invasive positive pressure ventilation for the treatment of severe stable chronic obstructive pulmonary disease: a prospective, multicentre, randomised, controlled clinical trial. Lancet Respir Med. 2014;2(9):698-705.

30. Contal O, Adler D, Borel JC, et al. Impact of different backup respiratory rates on the efficacy of noninvasive positive pressure ventilation in obesity hypoventilation syndrome: a randomized trial. Chest. 2013; 143(1):37-46.

31. Murphy PB, Brignall K, Moxham J, Polkey MI, Davidson AC, Hart N. High pressure versus high intensity noninvasive ventilation in stable hypercapnic chronic obstructive pulmonary disease: a randomized crossover trial. Int J Chron Obstruct Pulmon Dis. 2012;7:811-818.
32. Biselli P, Grossman PR, Kirkness JP, et al. The effect of increased lung volume in chronic obstructive pulmonary disease on upper airway obstruction during sleep. J Appl Physiol. 2015;119(3):266-271.

33. Laghi F, Segal J, Choe WK, Tobin MJ. Effect of imposed inflation time on respiratory frequency and hyperinflation in patients with chronic obstructive pulmonary disease. Am J Respir Crit Care Med. 2001;163(6):1365-1370.

\section{Publish your work in this journal}

The International Journal of COPD is an international, peer-reviewed journal of therapeutics and pharmacology focusing on concise rapid reporting of clinical studies and reviews in COPD. Special focus is given to the pathophysiological processes underlying the disease, intervention programs, patient focused education, and self management protocols.

\section{Dovepress}

This journal is indexed on PubMed Central, MedLine and CAS. The manuscript management system is completely online and includes a very quick and fair peer-review system, which is all easy to use. Visit http://www.dovepress.com/testimonials.php to read real quotes from published authors.

Submit your manuscript here: http://www.dovepress.com/international-journal-of-chronic-obstructive-pulmonary-disease-journal 